\title{
Mental Health vs Mental Toughness in Athlete
}

\author{
Rayinda Faizah \\ \{rayinda.faizah.ummgl.ac.id
}

Psychology, Muhammadiyah Magelang University, Magelang, Indonesia

\begin{abstract}
Mental health and mental toughness are two psychological attributes that are often inherent in an athlete. This review appraise the evidence base regarding the mental health and mental toughness of athletes. Methods : A systematic search of the Routledge, Elsevier, SAGE, and Google Scholar databases, up to and including February 2021, was conducted. The search yielded a total of 26 records. Results : Mental health in athletes has a role in being able to maintain the psychological stability of athletes, being able to actualize their potential, and not raising psychological complaints before, during or after the competition. Meanwhile, mental toughness acts as an important psychological aspect for athletes when faced with stressful or unpredictable situations.
\end{abstract}

Keywords: Mental health, mental toughness, athlete.

\section{Introduction}

Mental health issues and mental toughness are psychological attributes that are often discussed in athletes. There are still many who think that mental health and mental resilience are the same attributes. Even though the two attributes are very different. Athletes are often associated with the attribute of mental endurance, where the hope is that an athlete must be able to survive mentally in stressful situations both when doing training and just before the race. An athlete is required to be able to survive and must not fall even when under stressful conditions. While mental health is a situation where a person is able to self-actualize and there are no complaints about mental disorders in him.

The results showed that athletes who have mental toughness in the low category show several symptoms of mental disorders such as burnout and depression [1]. The presence of mental problems in the athlete indicates that he is not mentally healthy. The high stigma against people with mental health, especially athletes, makes them not open and do not receive appropriate treatment [2], [3]. Mental health cannot be separated from physical health in athletes, mental health can reduce the appearance of psychological disorders when athletes experience injuries [4]. The results of other studies indicate that mental toughness is related to anxiety, where high mental toughness in athletes will have an effect on the athlete's anxiety level being low. This condition indicates that training is needed to increase mental toughness [5]-[7]. It is important for athletes to recognize that mental health and mental toughness are important. Because the mental health condition and mental toughness are expected to be able to improve their performance in sports activities.

The purpose of this study was to examine the role of mental health and mental toughness in athletes. From the results of this study, it is hoped that mental health and mental toughness will be of concern to related parties around the athlete environment, such as coaches and sports 
organizations, so that they are able to improve athletes' achievement and performance in competitions.

\section{Methods}

The research method in this study uses a systematic review literature method. Researchers collected articles from several publishers, namely Their Routledge, Elsevier, SAGE, and Google Scholar data bases. The collection of articles was carried out during February 2021. Based on the search, 26 articles were obtained that match the research criteria.

The first stage carried out was the researcher conducted an initial screening by looking at the title and abstract that were in accordance with the theme. The keywords used are mental health and mental toughness.

The second stage is selecting articles according to predetermined criteria. These criteria include: 1) Articles published in the year of at least 2000;2) Discusses mental health in athletes and / or mental toughness in athletes; 3) Types of articles can be research articles and review articles.

The third stage, the researcher carried out the data extraction stage. Researchers extracted data according to a template that had been prepared, namely the type of research and design, population, research objectives, results and research findings.

\section{Results and Discussion}

\subsection{Mental health in athlete}

Mental health is a condition in which mentality can function optimally, be able to be active and productive, be able to establish social relationships, and be able to adapt to uncertain environments [8]. Mental health is not only a condition characterized by the absence of mental disorders, but also how individuals are able to recognize inner potential that can be used to improve one's mental well-being [8].

For athletes, mental health is an important and must-have aspect. This is because athletes are more often exposed to uncertain situations [9]. This uncertain situation demands athletes to adapt quickly. When athletes are unable to adapt to a stressful environment, athletes will complain of mental health problems such as stress, depression, depression, and even panic [9][12].

Athletes tend to be prone to complaints related to mental health when the match lasts until after the match [9]. This is because these situations are unpredictable, such as the result of the match not as expected. In addition, athletes who are in the transition stage from adolescence to adulthood and are currently pursuing higher education are also reported to experience higher distress [10]. In addition, the presence of high competitive power between athletes often results in mental health problems [13].

The emergence of mental health problems is also influenced by gender. The results showed that female athletes have a higher stress score than male athletes. This is because women still have difficulty expressing their emotions to others compared to men [14]. Apart from these differences, hormonal and biological differences also have an effect [14]. Another factor is dissatisfaction with achievement, where conditions of failure to achieve predetermined targets 
result in athletes complaining of mental health problems [11]. In addition, physical health problems also affect the mental health of athletes. Athletes who experience injuries have reportedly complained of several conditions related to problems in mental health [12]. Athletes are required to have excellent physical condition, but when the athlete is injured, there will be a concern that the athlete's performance when competing will decrease. Athletes who experience injuries will receive more comprehensive assistance and treatment, namely a recovery program that not only focuses on physical recovery but also on mental recovery [15].

Mental health conditions in athletes need to be maintained or improved because this condition has an impact on the athlete's performance [8], [16]. Athletes with good mental health conditions are expected to be able to show their full potential during the match.

Efforts to maintain the mental health of athletes must involve multidisciplinary disciplines and professions. Here, not only athletes and coaches play a role, but there is also a need for the participation of psychologists, psychiatrists, or doctors to provide special treatment related to mental problems of athletes [9].

\subsection{Mental toughness in athlete}

Mental toughness is one of the psychological attributes of an individual which includes how to integrate all the potential that is owned in the face of uncertain situations so as to keep the individual away from stressful or depressed conditions [17]. This mental toughness can be manifested in a person in the form of self-efficacy, optimism, motivation, enthusiasm, and other positive aspects of mental health [17]. The presence of good self-efficacy in athletes is expected to be able to improve athletes' performance when competing [18].

Mental toughness is a psychological attribute that is often inherent in athletes. Because with the presence of mental toughness in athletes, it is expected that they can eliminate the symptoms of mental disorders such as depression, stress and anxiety [19]. In addition, mental toughness is identical with self-confidence, ability to rise from failure, perseverance, being able to handle problems effectively and being able to maintain concentration even though situations are not conducive [20].

Athletes who have mental toughness have several indicators, including being able to face challenges, being able to learn from bad experiences, self-confidence, and low levels of depression, anxiety and stress [19]. When athletes have good mental toughness, it is hoped that they will increase their commitment to continue to play an active role and strive to improve their inner performance [21]. Athletes with mental toughness will have a high sense of competitiveness, achievement motivation and stable performance during the race [22].

The aspects needed by athletes to achieve mental toughness are generally good coping skills in situations or demands in sports such as competition, training and lifestyle, have a good commitment to stay focused and confident under pressure [23]. Mental toughness is influenced by several internal factors, namely narcissism, competition, self-welfare, self-concept, psychological abilities, self-insight, self-esteem, the need for satisfaction, and is also influenced by external factors, namely the existence of training programs, education, physical training, coaches and relationships. with coach and gender [24].

The effect of mental toughness on athletes has been shown to improve athlete performance [22]. With this good performance it will increase the athlete's success in the match. Mental toughness in athletes can be improved through a process of learning, experience and environmental influences [25]. The learning process can be done by involving athletes in activities that aim to increase mental toughness [26]. With activities such as training, it is hoped that they will be able to encourage athletes to develop their psychological strength and be able 
to identify what is needed to develop themselves [20]. Experience how to deal with and solve problems will also affect mental toughness of athletes. When athletes use positive coping in dealing with problems, it is hoped that their mental toughness will also be formed. The influence of the environment, where the behavior and mindset of the people around him will also have an influence on the condition of his mental toughness.

\subsection{Role mental health and mental toughness in athlete}

Mental toughness is a positive manifestation or indicator to create a healthy mental condition in athletes [17]. The concepts of mental toughness and mental health tend to overlap in a positive way, namely the perspective on stress.

Some of the factors that increase stressors in athletes include the sports environment, personal problems, the atmosphere of competition and sports organization. There are some athletes who are prone to mental health problems due to the inability to manage their training time, due to lack of commitment, failure to compete, injury, or problems with family or friends. This condition can lead to stress, depression, or anxiety in athletes.

Athletes who are not in a mentally healthy condition will find it difficult to actualize their potential, find it difficult to face uncertain match situations, lack motivation and even be unable to rise from defeat. The condition that appears shows that the athlete does not have mental toughness. Mental toughness plays a role in the personality aspects and sports activities of athletes that can improve psychological aspects and prevent mental health problems.

The aspects of mental health and mental toughness in athletes have a causal and inseparable relationship. Athletes who are in a mentally healthy condition are expected to have good mental toughness and vice versa.

Athletes are expected to have a mentally healthy condition so that athletes do not have complaints related to psychological problems before competing until after competing, there are no problems related to social aspects, are able to actualize their potentials, and have psychological toughness in dealing with various stressful situations. To maintain a healthy mental condition and mental toughness, athletes need help from various parties such as family, friends, coaches, and psychologists.

\section{Conclusion}

Mental health and mental toughness have a very important role for the psychological development of athletes. The presence of these two attributes is complementary. Mental health in athletes has a role in being able to maintain the psychological stability of athletes, being able to actualize their potential, and not raising psychological complaints before, during or after the competition. Meanwhile, mental toughness acts as an important psychological aspect for athletes when faced with stressful or unpredictable situations. Here athletes are expected to have good psychological toughness and resilience in themselves. Good mental toughness in athletes can be an indicator that the athlete is in a healthy mental state. The attributes of mental health and mental toughness in athletes are expected to improve athletes' performance when competing. Therefore, athletes need to get guidance and training that aims to maintain or improve mental health and mental toughness of athletes.

\section{Acknowledgements}


This research was made possible because of assistance from the Institutional Vision Revitalization Research (PRVI) grant program initiated by the Muhammadiyah University of Magelang. The researcher would like to thank the funding party so that this research can be completed.

\section{References}

[1] A. M. Gerber et al., "Effects of stress and mental toughness on burnout and depressive symptoms: A prospective study with young elite athletes," J. Sci. Med. Sport, vol. 21, no. 12, hal. 1-19, 2018.

[2] J. M. Castaldelli-maia et al., "Mental health symptoms and disorders in elite athletes : a systematic review on cultural influencers and barriers to athletes seeking treatment," Br J Sport. Med, no. May, hal. 1-16, 2019.

[3] A. L. Rao dan E. Hong, Overcoming the stigma of mental health in sport. Springer, Cham, 2020.

[4] C. L. Reardon et al., "Mental health in elite athletes : International Olympic Committee consensus statement ( 2019 )," Br J Sport. Med, vol. 53, hal. 667-699, 2019.

[5] A. Ikhram, M. Jufri, dan A. Ridfah, "Mental Toughness dan Competitive Anxiety Pada Atlet Karate UNM," J. Psikol. Perseptual, vol. 5, no. 2, hal. 100-109, 2020.

[6] R. Kalinin, R. Balázsi, I. Péntek, Ștefania Duică, dan I. Hanțiu, "Relationship between competitive anxiety and mental toughness : a latent regression analysis," Heal. Sport. Rehabil. Med., vol. 20, no. 2, hal. 70-74, 2019.

[7] N. M. Rasyid, J. Low, F. Lee, dan R. Y. Tengah, "Relationship Between Mental Toughness, Sports Competition Anxiety and Performance among Women's Hockey Team," Adv. Soc. Sci. Educ. Humanit. Res., vol. 362, no. Acpes, hal. 94-97, 2019.

[8] R. J. Schinke dan N. B. Stambulova, "International society of sport psychology position stand: Athletes ' mental health, performance, and development," Int. J. Sport Exerc. Psychol., vol. 00, no. 0 , hal. 1-18, 2017.

[9] K. Henriksen et al., "Athlete mental health in the Olympic / Paralympic quadrennium : a multisocietal consensus statement Athlete mental health in the Olympic / Paralympic quadrennium : a multi-societal consensus statement," Int. J. Sport Exerc. Psychol., vol. 0, no. 0, hal. 1-18, 2020.

[10] J. J. Moreland, K. A. Coxe, dan J. Yang, "Collegiate athletes ' mental health services utilization : A systematic review of conceptualizations, operationalizations, facilitators , and barriers," J. Sport Heal. Sci., vol. 7, no. 1, hal. 58-69, 2018.

[11] R. L. Foskett dan F. Longstaff, "The mental health of elite athletes in the United Kingdom," J. Sci. Med. Sport, vol. 21, no. 8, hal. 765-770, 2017.

[12] A. Gulliver, K. M. Griffiths, A. Mackinnon, P. J. Batterham, dan R. Stanimirovic, "The mental health of australian elite athletes," J. Sci. Med. Sport, vol. 18, no. 3, hal. 255-261, 2015.

[13] C. Swann et al., "Youth sport as a context for supporting mental health: Adolescent male perspectives," Psychol. Sport Exerc., vol. 35, no. August 2017, hal. 55-64, 2018.

[14] C. P. Herrero, N. Jejurikar, dan C. W. Carter, "The psychology of the female athlete: how mental health and wellness mediate sports performance, injury and recovery," Ann. Jt., hal. 1-8, 2020.

[15] S. A. Vella et al., "Sports-based mental health promotion in Australia : Formative evaluation," Psychol. Sport Exerc., vol. 45, no. November 2018, hal. 101560, 2019.

[16] S. Eloranta, J. Franck, dan C. Akesdotter, "The prevalence of mental health problems in elite athletes," J. Sci. Med. Sport, vol. 23, no. 4, hal. 329-335, 2019.

[17] D. F. Gucciardi, S. Hanton, dan S. Fleming, "Are mental toughness and mental health contradictory concepts in elite sport? A narrative review of theory and evidence," J. Sci. Med. Sport, vol. 20, no. 3, hal. 6-10, 2016.

[18] E. Setiawan, I. A. Patah, C. Bapista, M. E. Winarno, B. Sabino, dan E. F. Amalia, "Self-efficacy dan mental toughness : Apakah faktor psikologis berkorelasi dengan performa atlet?," J. Keolahragaan, vol. 8, no. 2, hal. 158-165, 2020.

[19] N. Malhotra dan R. Kaur, "Mental Toughness in Relation with Mental Health of Sports Persons," 
Am. Jpurnal Sport. Sci., vol. 5, no. 5, hal. 31-34, 2017.

[20] R. C. Thelwell, B. A. Such, N. J. V Weston, J. D. Such, dan I. A. Greenlees, "Developing mental toughness : Perceptions of elite female gymnasts," Int. J. Sport Exerc. Psychol., vol. 8, no. December 2014, hal. 37-41, 2011

[21] L. Crust dan K. Azadi, "Mental toughness and athletes ' use of psychological strategies," Eur. J. Sport Sci., vol. 10, no. December 2014, hal. 37-41, 2010.

[22] R. G. Cowden, "Mental toughness and success in sport: A review and prospect," Open Sports Sci. J., vol. 27, no. 0, hal. 1-14, 2017.

[23] G. C. Liew, G. Kuan, N. Chin, dan H. A. Hashim, "Mental toughness in sport Systematic review and future," Ger. J. Exerc. Sport Res., no. March 2020, 2019.

[24] D. B. Aryanto dan A. Larasati, "Factors Influencing Mental Toughness," in 5th ASEAN Conference on Psychology, Counselling and Humanities, 2020, vol. 395, no. Acpch 2019, hal. 307-309.

[25] L. Crust, "Mental toughness in sport : a review," Int. J. Sport Exerc. Psychol., vol. 5, no. July 2012, hal. 37-41, 2011.

[26] S. Tibbert, T. Morris, dan M. Andersen, "Mental toughness and recovery in athletes," J. Sci. Med. Sport, vol. 12, no. 2009, 2008. 